\title{
Analisis Perencanaan Tebal Perkerasan Lentur Jalan Dengan Menggunakan Metode Analisa Komponen Bina Marga 1987 Dan Rencana Anggaran Biaya Konstruksinya Pada Ruas Jalan Banjaran - Balamoa
}

\author{
Weimintoro ${ }^{1}$, Okky Hendra Hermawan ${ }^{2}$, Teguh Haris, S. ${ }^{3}$ \\ ${ }^{1,2,3}$ Teknik Sipil Universitas Pancasakti Tegal \\ E-mail: weimintoro@yahoo.co.id
}

\begin{abstract}
ABSTRAK: Pada penelitian ini dilakukan analisis untuk tebal lapis perkerasan jalan dengan menggunakan Metode Analisa Komponen Bina Marga 1987 sehingga nantinya akan diperoleh tebal lapis perkerasan yang sesuai dengan kebutuhan. Data CBR diperoleh dari hasil DCP lapangan yang dilakukan pada proyek Peningkatan Jalan Banjaran-Balamoa. Ruas jalan yang diteliti adalah jalan Banjaran-Balamoa dengan panjang jalan yang diteliti $1000 \mathrm{~m}$ atau pada KM 3 sampai dengan KM 4 dan lebar jalannya adalah 7 m. Untuk umur rencana direncanakan 10 tahun, angka pertumbuhan lalu lintas sebesar 5\% dan klasifikasi fungsional jalan adalah jalan kolektor. Dari hasil perhitungan dan pembahasan secara keseluruhan untuk perencanaan tebal perkerasan jalan ini menggunakan Laston MS $744 \mathrm{~kg}$ dengan tebal minimum $5 \mathrm{~cm}$ untuk lapis permukaan, Laston Atas MS $590 \mathrm{~kg}$ dengan tebal $10 \mathrm{~cm}$ untuk lapis pondasi atas dan Sirtu/Pitrun Kelas B dengan tebal diperoleh $5 \mathrm{~cm}$ untuk lapis pondasi bawah.
\end{abstract}

Kata Kunci : Perkerasan Jalan, Tebal Perkerasan Jalan, Analisa Komponen Bina Marga 1987

\section{PENDAhUluan}

Jalan merupakan sarana transportasi yang kemudian berkembang menjadi sarana perhubungan dalam melakukan aktifitas perekonomian baik itu aksesibilitas maupun mobilitas barang dan jasa. Akibat dari tuntutan perkembangannya, maka jalan harus menyesuaikan tingkat pelayaannya. Padatnya lalu lintas dan pelanggaran pada pemakai jalan serta pemilik kendaraan besar yang melewati seringkali membuat konstruksi pada perkerasan jalan mengalami kerusakan.

Salah satu alternatif pemecah untuk dapat mengatasi kerusakan struktur akibat beban dan kepadatan yang berlebihan di jalan Banjaran - Balamoa adalah dengan merencanakan lapis perkerasan pada jalan tersebut sesuai dengan kebutuhannya. Dengan adanya perencanaan lapis perkerasan ini diharapkan dapat mengurangi kerusakan pada struktur perkerasan serta memberikan kenyamanan pada penggunanya dan dapat memperlancar arus lalu lintas.

Pada penelitian ini akan dilakukan analisa tentang tebal perkerasan jalan yang dibutuhkan pada ruas jalan Banjaran - Balamoa. Pemilihan lokasi tersebut dikarenakan konstruksi pada jalannya terjadi kerusakan yang cukup tinggi. Banyaknya kendaraan berat yang melewati sering pula mengakibatkan konstruksi jalan lebih dulu mengalami kerusakan, oleh karena itu Tugas Akhir ini akan membahas tentang tebal lapis perkerasan pada ruas Banjaran - Balamoa, sehingga diperoleh konstruksi jalan yang mampu untuk menahan beban kendaraan.

\section{METODOLOGI PENELITIAN}

Lokasi yang dijadikan untuk penelitian perencanaan tebal lapis perkerasan jalan adalah ruas Jalan BanjaranBalamoa Kecamatan Pangkah Kabupaten Tegal, tepatnya pada KM 3 sampai dengan KM 4. Dengan panjang total $5300 \mathrm{~m}$ (dimulai dari pertigaan Banjaran sampai dengan perempatan Balamoa). Dalam pelaksanaannya penelitian ini terbagi menjadi tiga tahapan, yaitu :

\section{1) Tahap Persiapan}

Tahap persiapan ini adalah tahap awal sebelum dimulainya tahap-tahap selanjutnya

\section{2) Tahap Pengumpulan Data}

Terdapat dua jenis data yaitu data primer dan data sekunder. Data primer adalah data yang diperoleh langsung dari hasil pengamatan di lapangan, data tersebut adalah hasil survey lalu lintas harian rata-rata (LHR). Sedangkan data sekunder adalah data yang diperoleh dari pihak lain

\section{3) Tahap Pengolahan Data}

Pengolahan data disini terdiri dari perhitungan tebal pengerasan jalan dengan metode analisa komponen bina marga 1987 dan perhitungan rencana anggaran biaya (RAB) dan untuk lengkapnya terdapat pada Gambar 1.

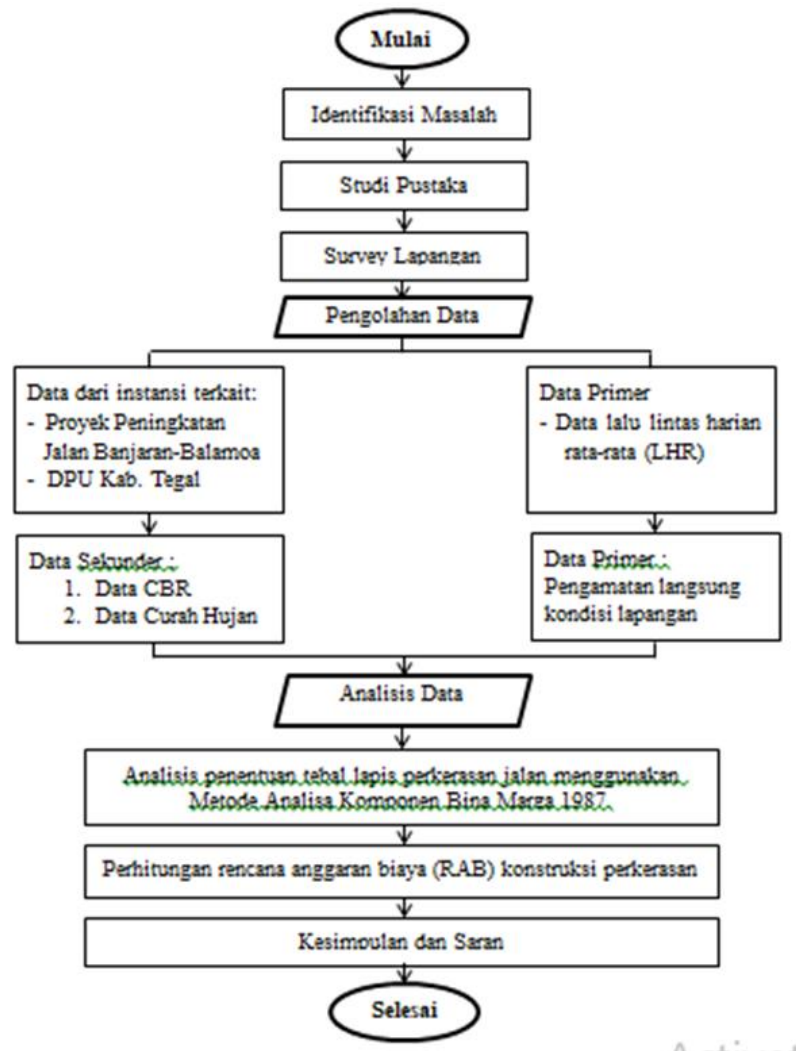

Gambar 1. Diagram Alur Penelitian 


\section{HASIL PENELITIAN DAN PEMBAHASAN}

1) Data lalu lintas

Data lalu lintas yang digunakan adalah hasil survey langsung ke lokasi, dengan pengamatan selama 12 jam/hari, yang dilakukan selama lima hari denga hasil pada Tabel 1 berikut.

Tabel 1. LHR Pada Ruas Jalan Banjaran-Balamoa

\begin{tabular}{|l|l|c|c|c|c|c|c|}
\hline No. & $\begin{array}{l}\text { Jenis } \\
\text { Kendar } \\
\text { aan }\end{array}$ & $\begin{array}{c}\text { Hari } \\
\text { ke-1 }\end{array}$ & $\begin{array}{c}\text { Hari } \\
\text { ke-2 }\end{array}$ & $\begin{array}{c}\text { Hari } \\
\text { ke-3 }\end{array}$ & $\begin{array}{c}\text { Hari } \\
\text { ke-4 }\end{array}$ & $\begin{array}{c}\text { Hari } \\
\text { ke-5 }\end{array}$ & $\begin{array}{c}\text { Rata } \\
\text {-rata }\end{array}$ \\
\hline 1. & $\begin{array}{l}\text { Mobil } \\
\text { Penump } \\
\text { ang }\end{array}$ & $\begin{array}{c}1.72 \\
5\end{array}$ & $\begin{array}{c}1.55 \\
8\end{array}$ & $\begin{array}{c}1.48 \\
9\end{array}$ & $\begin{array}{c}1.61 \\
5\end{array}$ & $\begin{array}{c}1.46 \\
5\end{array}$ & $\begin{array}{c}1.57 \\
3\end{array}$ \\
\hline 2. & Pick Up & 265 & 228 & 224 & 259 & 250 & 245 \\
\hline 3. & $\begin{array}{l}\text { Bis } \\
\text { kecil }\end{array}$ & 9 & 8 & 6 & 7 & 4 & 7 \\
\hline 4. & $\begin{array}{l}\text { Bis } \\
\text { besar }\end{array}$ & 0 & 2 & 1 & 4 & 3 & 2 \\
\hline 5. & $\begin{array}{l}\text { Truck } 2 \\
\text { as }\end{array}$ & 213 & 264 & 239 & 184 & 213 & 223 \\
\hline 6. & $\begin{array}{l}\text { Truck 3 } \\
\text { as }\end{array}$ & 6 & 6 & 5 & 3 & 4 & 5 \\
\hline 7. & Trailer & 1 & 3 & 2 & 0 & 0 & 1 \\
\hline
\end{tabular}

2) California Bearing Ratio (CBR)

Dari hasil pengujian CBR didapat seperti pada Tabel 2 berikut.

Tabel. 2 Nilai CBR Lapangan Pada Ruas Jalan Banjaran Balamoa

\begin{tabular}{|c|c|}
\hline Titik Uji STA & Nilai CBR (\%) \\
\hline 0+700 (kiri) & 9 \\
\hline 1+700 (kanan) & 9 \\
\hline 3+000 (kiri) & 9 \\
\hline 3+800 (kanan) & 9 \\
\hline 4+300 (kiri) & 9 \\
\hline 5+100 (kiri) & 9 \\
\hline
\end{tabular}

Berdasarkan Tabel 2 diatas maka didapat nialai CBR sebesar 9\% di semua titik STA yang diambil. Sedangkan nilai $\mathrm{R}$ berdasarkan jumlah titik pengujian terdapat pada Tabel 3.

Tabel 3. Nilai R Berdasarkan Jumlahh Titik Pengujian

\begin{tabular}{|c|c|}
\hline $\begin{array}{c}\text { Jumlah titik } \\
\text { pengujian }\end{array}$ & Nilai R \\
\hline $\mathbf{2 2}$ & 1,41 \\
\hline $\mathbf{3}$ & 1,91 \\
\hline $\mathbf{4}$ & 2,24 \\
\hline $\mathbf{5}$ & 2,48 \\
\hline $\mathbf{6}$ & $\mathbf{2 , 6 7}$ \\
\hline $\mathbf{7}$ & 2,83 \\
\hline $\mathbf{8}$ & 2,96 \\
\hline $\mathbf{9}$ & 3,08 \\
\hline$>\mathbf{1 0}$ & 3,18 \\
\hline
\end{tabular}

Menghitung CBR Segmen

CBR segmen $=$ CBR rata-rata $-($ CBR Maks - CBR Min $) /$ $\mathrm{R}$

$$
=9-(9-9) / 2,67=9 \%
$$

Perhitungan Tebal Perkerasan Lentur Jalan Dengan Metode Analisa Komponen Bina Marga 1987

\section{Data}

Nama Link

Umur rencana

: Banjaran-Balamoa

: 10 tahun

Jalan direncanakan dibuka : 2021

Faktor pertumbuhan tahun 2019-2020:5\% ( Sumber

:Peningkatan Jalan Banjaran-Balamoa)

Koefisien distribusi kendaraan (C) : 0,5 (2 lajur, 2 arah)

\section{Perhitungan}

Angka ekivalen (E) untuk masing-masing jenis

kendaraan

- Mobil penumpang, berat total 2 ton

- Bebas as depan 1 ton, beban as belakang 1 ton, = $0,0002+0,0002=0,0004$

- Pick up, berat total 3 ton

- Beban as depan 1 ton, beban as belakang 2 ton, = $0,0002+0,0036=0,0038$

- $\quad$ Bis kecil/sedang, berat total 7 ton Beban as depan 2 ton, beban as belakang 5 ton, $=0,0036+0,1410=$ 0,1446

- $\quad$ Bis besar, berat total 9 ton

Beban as depan 3 ton, beban as belakang 6 ton, = $0,0183+0,2923=0,3106$

- $\quad$ Truck 2 as, berat total 13 ton Beban as depan 5 ton, beban as belakang 8 ton, = $0,1410+0,9238=1,0648$

- $\quad$ Truck 3 as, berat total 20 ton

Beban as depan 6 ton, beban as belakang 14 ton, = $0,2923+0,7452=1,0375$

- $\quad$ Trailer, berat total 42 ton

Beban as depan 8 ton, beban as belakang 22 ton, beban 2 as depan 6 ton

$=0,9238+4,5439+0,5846=6,0523$

Menghitung LHR pada awal umur rencana (2021)

$\mathrm{LHR}_{2021}=\mathrm{LHR}_{2020} \times(1+\mathrm{i})^{\mathrm{n}}$

Mobil penumpang $=1.573 \times(1+0,05)^{1}=1.651,20$

Pick up $\quad=245 \times(1+0,05)^{1}=257,46$

Bis kecil $=7 \times(1+0,05)^{1}=7,14$

Bis besar $\quad=2 \times(1+0,05)^{1}=2,10$

Truck 2 as $\quad=223 \times(1+0,05)^{1}=233,73$

Truck 3 as $\quad=5 \times(1+0,05)^{1}=5,04$

Trailer $\quad=1 \times(1+0,05)^{1}=1,26$

Menghitung LHR pada akhir umur rencana (2031)

$\mathrm{LHR}_{2031}=\mathrm{LHR}_{2021} \times(1+\mathrm{i})^{\mathrm{n}}$

Mobil penumpang $=1.651,20 \times(1+0,05)^{10}=2689,6797$

Pick up $\quad=257,46 \times(1+0,05)^{10}=419,3752$

Bis kecil $\quad=\quad 7,14 \times(1+0,05)^{10}=11,6303$

Bis besar $\quad=\quad 2,1 \times(1+0,05)^{10}=3,4207$

Truck 2 as $\quad=233,73 \times(1+0,05)^{10}=380,7215$

Truck 3 as $\quad=\quad 5,04 \times(1+0,05)^{10}=8,2096$

Trailer $\quad=\quad 1,26 \times(1+0,05)^{10}=2,0524$

\section{Menghitung Lintas Ekivalen Permulaan (LEP)}

$\mathrm{LEP}=\mathrm{LHR}_{2021} \times \mathrm{C} \times \mathrm{E}$

Untuk nilai lalu lintas ekivalen permulaan terdapat pada Tabel 4 berikut.

Tabel 4. Nilai Lintas Ekivalen Permulaan (LEP)

\begin{tabular}{|l|c|c|c|c|}
\hline $\begin{array}{c}\text { Jenis } \\
\text { Kendaraan }\end{array}$ & $\begin{array}{c}\text { LHR } \\
\mathbf{2 0 2 1}\end{array}$ & $\mathbf{C}$ & $\mathbf{E}$ & LEP \\
\hline $\begin{array}{l}\text { Mobil } \\
\text { penumpang }\end{array}$ & $1.651,2$ & 0,5 & 0,0004 & 0,3302 \\
\hline
\end{tabular}




\begin{tabular}{|l|c|c|c|c|}
\hline Pick up & 257,46 & 0,5 & 0,0038 & 0,4892 \\
\hline Bis kecil & 7,14 & 0,5 & 0,1446 & 0,5162 \\
\hline \multicolumn{5}{|c|}{ Lanjutan Tabel 4} \\
\hline Bis besar & 2,10 & 0,5 & 0,3106 & 0,3261 \\
\hline Truck 2 as & 233,73 & 0,5 & 1,0648 & 124,4379 \\
\hline Truck 3 as & 5,04 & 0,5 & 1,0375 & 2,6145 \\
\hline Trailer & 1,26 & 0,5 & 6,023 & 3,8129 \\
\hline $\boldsymbol{\Sigma}$ LEP & & & & $\mathbf{1 3 2 , 5 2 7 1}$ \\
\hline
\end{tabular}

\section{Menghitung Lintas Ekivalen Akhir (LEA)}

$\mathrm{LEA}=\mathrm{LHR}_{2031} \times \mathrm{C} \times \mathrm{E}$

Untuk hasil perhitungan nilai lalu lintas ekivalen permulaan terdapat pada Tabel 5 berikut.

Tabel 5. Nilai Lintas Ekivalen Akhir (LEA)

\begin{tabular}{|l|c|c|c|c|}
\hline Jenis Kendaraan & LHR 2031 & C & E & LEA \\
\hline $\begin{array}{l}\text { Mobil } \\
\text { penumpang }\end{array}$ & $2.689,6797$ & 0,5 & 0,0004 & 0,5379 \\
\hline Pick up & 419,3725 & 0,5 & 0,0038 & 0,7968 \\
\hline Bis kecil & 11,6303 & 0,5 & 0,1446 & 0,8409 \\
\hline Bis besar & 3,4207 & 0,5 & 0,3106 & 0,25312 \\
\hline Truck 2 as & 380,7215 & 0,5 & 1,0648 & 202,6961 \\
\hline Truck 3 as & 8,2096 & 0,5 & 1,0375 & 4,2587 \\
\hline Trailer & 2,0524 & 0,5 & 6,023 & 6,2109 \\
\hline L LEA & & & & $\mathbf{2 1 5 , 8 7 2 6}$ \\
\hline
\end{tabular}

Menghitung Lintas Ekivalen Tengah
$\begin{aligned} \text { LET } & =(\text { LEP }+ \text { LEA }) / 2 \\ & =(132,5271+215,8726) / 2 \\ \text { LET } & =174,1999\end{aligned}$

Menghitung Lintas Ekivalen Rencana (LER)

LER = LET $\times$ UR/10

$=174,1999 \times 10 / 10$

LER $=174,1999$

\section{Mencari nilai DDT}

CBR segmen sebesar 9\% setelah dikorelasikan dengan Nomogram DDT dan CBR di dapat nilai daya dukung tanah (DDT) sebesar 5,8. Atau bisa dihitung dengan menggunakan rumus sebagai berikut dan pada Gambar 2. DDT $=4,3 \times \log 9+1,7$

$$
\begin{aligned}
& =4,3 \times 0,9543+1,7 \\
& =5,8
\end{aligned}
$$

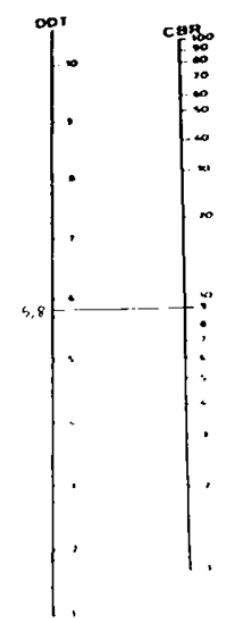

Gambar 2. Nilai DDT Pada Ruas Jalan Banjaran-Balamoa
Tabel 6. Presentase Jumlah Kendaraan Berat

\begin{tabular}{|c|c|c|}
\hline $\begin{array}{c}\Sigma \text { kendaraan } \\
\text { keseluruhan }\end{array}$ & $\begin{array}{c}\Sigma \text { kendaraan } \\
\text { berat } \\
(\geq \mathbf{1 3} \text { ton })\end{array}$ & $\begin{array}{c}\text { Presentase } \\
(\boldsymbol{\%})\end{array}$ \\
\hline $\mathbf{2 0 5 5}$ & 229 & $11,12 \%$ \\
\hline
\end{tabular}

\section{Faktor Regional (FR)}

Faktor regional (FR) dapat ditentukkan yaitu data-datanya sebagai berikut : kelandaian $<6 \%$, presentase kendaraan berat $11,12 \%$ serta data curah hujan $<900$ $\mathrm{mm} / \mathrm{th}$, maka nilai FR didapat 0,5 .

Indeks Permukaan Pada Akhir Umur Rencana (IPt) dan Indeks Permukaan Pada Awal Umur Rencana (IPo)

Untuk menentukkan nomogram tebal perkerasan lentur, maka IPt dan IPo harus diketahui terlebih dahulu. IPt ini ditentukkan berdasarkan nilai LER dan klasifikasi jalan. Pada perhitungan diperoleh nilai LER sebesar 174,1999 sedangkan untuk klasifikasi jalan pada ruas jalan Banjaran-Balamoa adalah jalan kolektor. Dengan demikian diperoleh nilai $\mathrm{IPt}=2,0$

Jalan direncanakan menggunakan lapis permukaan aspal beton, maka nilai IPo didapat IPo $\geq 4$.

\section{Menentukkan Indeks Tebal Perkerasan (ITP)}

Memplotkan masing-masing nilai dari DDT, LER, FR kemudian di tarik garis lurus sampai memotong garis ITP seperti pada Tabel 7 dan Gambar 3.

Tabel 7. Harga ITP

$\begin{array}{cc}\text { DDT } & \text { LER } \\ \mathbf{5 , 8} & 174,1999\end{array}$


Susunan perkerasan yang direncanakan :

Surface course digunakan beton aspal MS $744 \mathrm{~kg}$ dengan tebal minimum $=5 \mathrm{~cm}$. Base course digunakan beton aspal MS $590 \mathrm{~kg}$ dengan tebal minum $10 \mathrm{~cm}$. Lapis pondasi bawah (subbase course) digunakan sirtu/pitrun CBR 50 dengan tebal minimum dicari.

Maka didapat data sebagai berikut :

$$
\begin{array}{ll}
\mathrm{a}_{1}=0,4 & \mathrm{D}_{1}=5 \mathrm{~cm} \\
\mathrm{a}_{2}=0,14 & \mathrm{D}_{2}=10 \mathrm{~cm} \\
\mathrm{a}_{3}=0,12 & \mathrm{D}_{3}=?
\end{array}
$$

Mencari D3 dengan menggunakan rumus :

ITP $=\mathbf{a}_{1} \times \mathbf{D}_{1}+\mathbf{a}_{2} \times \mathbf{D}_{2}+\mathbf{a}_{3} \times \mathbf{D}_{3}$

$5,36=0,4 \times 5+0,28 \times 10+0,12 \times \mathrm{D}_{3}$

$5,36=2+2,8+0,12 \mathrm{D}_{3}$

$5,36=4,8+0,12 \mathrm{D}_{3}$

$0,13 \mathrm{D}_{3}=5,36-4,8$

$$
\begin{array}{lll}
\mathrm{D}_{3} & = & 0,56 / 0,12 \\
\mathrm{D}_{3} & = & 4,667 \mathrm{~cm} \sim 5 \mathrm{~cm}
\end{array}
$$

Sehingga susunan perkerasan akan digambarkan sebagai berikut (Gambar 4) :

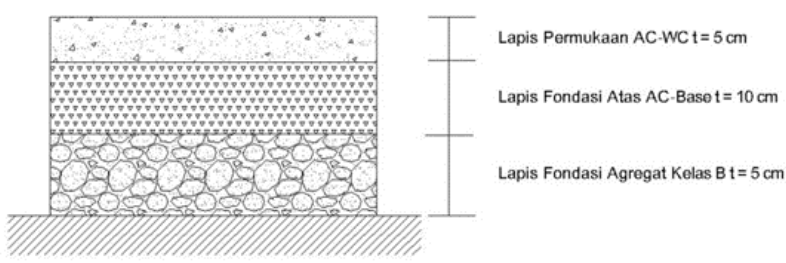

Gambar 4. Susunan pengerasan

\section{Rencana Angggaran Biaya (RAB)}

Rencana anggaran biaya (RAB) adalah perhitungan seluruh kegiatan pekerjaan konstruksi, yang bertujuan untuk memperkirakan biaya yang dibutuhkan dalam suatu konstruksi bangunan. Analisa harga satuan pekerjaan (AHSP) yang digunakan adalah AHSP Kabupaten Tegal Tahun 2019. Panjang jalan yang diteliti adalah $1000 \mathrm{~m}$ atau pada KM 3 sampai denan KM 4 dengan lebar jalan 7 m. Berikut uraian pekerjaannya.

Rekap Perhitungan Volume Pekerjaan

Untuk rekap perhitungan volume dari beberapa item pekerjaan terdapat pada Tabel 8 sampai Tabel 14 berikut.

1. Galian perkerasan berbutir

Tabel 8. Volume Galian Perkerasan Berbutir

\begin{tabular}{|c|c|c|c|c|}
\hline \multirow{2}{*}{ STA } & PANJANG & LEBAR & TEBAL & VOL. \\
\cline { 2 - 5 } & $\mathrm{m}$ & $\mathrm{m}$ & $\mathrm{m}$ & $\mathrm{m}^{3}$ \\
\hline $\begin{array}{c}\text { 3+000 s.d } \\
\text { 4+000 }\end{array}$ & 1000 & 7 & 0,20 & 1400 \\
\hline
\end{tabular}

2. Penyiapan badan jalan

Tabel 9. Volume Penyiapan Badan Jalan

\begin{tabular}{|c|c|c|c|}
\hline \multirow{2}{*}{ STA } & PANJANG & LEBAR & Luas. \\
\cline { 2 - 4 } & $\mathrm{m}$ & $\mathrm{m}$ & $\mathrm{m}^{2}$ \\
\hline 3+000 s.d 4+000 & 1000 & 7 & 7000 \\
\hline
\end{tabular}

3. Lapis fondasi agregat kelas B (LPB)

Tabel 10. Volume Lapis Agregat Kelas B

\begin{tabular}{|c|c|c|c|c|}
\hline \multirow{2}{*}{ STA } & PANJANG & LEBAR & TEBAL & VOL. \\
\cline { 2 - 5 } & $\mathrm{m}$ & $\mathrm{m}$ & $\mathrm{m}$ & $\mathrm{m}^{3}$ \\
\hline $\begin{array}{c}\text { 3+000 s.d } \\
\mathbf{4 + 0 0 0}\end{array}$ & 1000 & 7 & 0,05 & 350 \\
\hline
\end{tabular}

4. Lapis Resap Pengikat

Tabel 11. Kuantitas Lapis Resap Pengikat

\begin{tabular}{|c|c|c|c|c|}
\hline \multirow{2}{*}{ STA } & PANJANG & LEBAR & KOEF. & VOL. \\
\cline { 2 - 5 } & $\mathrm{m}$ & $\mathrm{m}$ & Liter/m ${ }^{2}$ & Liter \\
\hline $\begin{array}{c}\text { 3+000 s.d } \\
\mathbf{4 + 0 0 0}\end{array}$ & 1000 & 7 & 0,5 & 3500 \\
\hline
\end{tabular}

5. Lapis Perekat

\begin{tabular}{|c|c|c|c|c|c|c|}
\hline \multirow[t]{2}{*}{ STA } & $\begin{array}{c}\text { PANJA } \\
\text { NG }\end{array}$ & LEBAR & $\begin{array}{c}\text { TEBA } \\
\text { L }\end{array}$ & $\begin{array}{c}\text { VOL } \\
.\end{array}$ & KOEF & $\begin{array}{c}\text { KUANT } \\
.\end{array}$ \\
\hline & $\mathrm{m}$ & $\mathrm{m}$ & $\mathrm{m}$ & $\mathrm{m}^{3}$ & $t / m^{3}$ & Ton \\
\hline $\begin{array}{c}3+00 \\
0 \text { s.d } \\
4+00 \\
0\end{array}$ & 1000 & 7 & 0,10 & 700 & 2,29 & 1603 \\
\hline \multicolumn{7}{|c|}{ Lapis Aus AC-WC } \\
\hline & PANJANG & LEBAR & TEBAL & VOL & KOEF. & KUANT \\
\hline STA & $\mathrm{m}$ & $\mathrm{m}$ & $\mathrm{m}$ & $\mathrm{m}^{3}$ & $\mathrm{t} / \mathrm{m}^{3}$ & Ton \\
\hline $\begin{array}{c}3+00 \\
0 \text { s.d } \\
4+000 \\
\end{array}$ & 1000 & 7 & 0,05 & 700 & 2,29 & 801,5 \\
\hline
\end{tabular}

Tabel 12 Kuantitas Lapis Perekat

\begin{tabular}{|c|c|c|c|c|}
\hline \multirow{2}{*}{ STA } & PANJANG & LEBAR & KOEF. & VOL. \\
\cline { 2 - 5 } & $\mathrm{m}$ & $\mathrm{m}$ & Liter $/ \mathrm{m}^{2}$ & Liter \\
\hline $\begin{array}{c}\text { 3+000 s.d } \\
\text { 4+000 }\end{array}$ & 1000 & 7 & 0,05 & 3500 \\
\hline
\end{tabular}

6. Lapis fondasi AC-Base

Tabel 13. Kuantitas Lapis Fondasi AC-Base

\section{Perhitungan Rencana Anggaran Biaya (RAB)}

\begin{tabular}{|c|c|c|c|c|c|}
\hline & $\begin{array}{l}\text { DIVISI } 3 . \\
\text { PEKERJAAN } \\
\text { TANAH }\end{array}$ & $\begin{array}{l}\text { Satua } \\
\mathbf{n}\end{array}$ & Vol. & $\begin{array}{l}\text { Harga } \\
\text { Satuan } \\
(\mathbf{R p})\end{array}$ & $\begin{array}{l}\text { Jumlah Harga } \\
\text { (Rp) }\end{array}$ \\
\hline $\begin{array}{l}3.1 \\
(8)\end{array}$ & $\begin{array}{l}\text { Galian } \\
\text { Perkerasan } \\
\text { Berbutir }\end{array}$ & $\mathrm{m} 3$ & 1400 & $\begin{array}{l}275.57 \\
9,28\end{array}$ & $385.810 .995,24$ \\
\hline \multirow[t]{2}{*}{$\begin{array}{l}3.3 \\
(1) \\
\end{array}$} & $\begin{array}{l}\text { Penyiapan } \\
\text { Badan Jalan }\end{array}$ & $\mathrm{m} 2$ & 7000 & $\begin{array}{l}3.134,2 \\
8 \\
\end{array}$ & $21.939 .929,61$ \\
\hline & $\begin{array}{lr}\text { DIVISI } 5 . \\
\text { PERKERASA } \\
\text { N BERBUTIR }\end{array}$ & & & & \\
\hline \multirow[t]{2}{*}{$\begin{array}{l}5.1 . \\
(2) \mathrm{a}\end{array}$} & $\begin{array}{l}\text { Lapis Pondasi } \\
\text { Agregat Kelas } \\
\text { B }\end{array}$ & $\mathrm{m} 3$ & 350 & $\begin{array}{l}562.00 \\
3,23\end{array}$ & $196.701 .131,72$ \\
\hline & $\begin{array}{l}\text { DIVISI } 6 . \\
\text { PERKERASA } \\
\text { N ASPAL }\end{array}$ & & & & \\
\hline $\begin{array}{l}6.1 \\
(1)\end{array}$ & $\begin{array}{l}\text { Lapis Resap } \\
\text { Pengikat } \\
\text { Aspal } \\
\text { Cair/Emulsi } \\
\end{array}$ & Liter & 3500 & $\begin{array}{l}12.979, \\
25\end{array}$ & $45.527 .381,75$ \\
\hline $\begin{array}{l}6.1 \\
(2 a)\end{array}$ & $\begin{array}{l}\text { Lapis Perekat - } \\
\text { Aspal } \\
\text { Cair/Emulsi }\end{array}$ & Liter & 3500 & $\begin{array}{l}12.721 \\
79\end{array}$ & $44.526 .265,00$ \\
\hline $\begin{array}{l}6.3 \\
(5 a) \\
1\end{array}$ & $\begin{array}{l}\text { Laston Lapis } \\
\text { Aus (AC-WC) }\end{array}$ & Ton & 801,5 & $\begin{array}{l}1.479 .3 \\
62,87\end{array}$ & $1.185 .709 .339,45$ \\
\hline
\end{tabular}

Untuk rekap perhitungan Rencana Anggaran Biaya (RAB) dari beberapa item pekerjaan terdapat pada Tabel 15 berikut.

Tabel 15. Rencana Anggaran Biaya 


\begin{tabular}{|c|c|c|c|c|c|}
\hline \multicolumn{6}{|c|}{ Lanjutan Tabel 15} \\
\hline $\begin{array}{l}6.3 \\
(7 a) \\
1 \\
\end{array}$ & $\begin{array}{ll}\text { Laston } & \text { Lapis } \\
\text { Pondasi } & \text { (AC- } \\
\text { Base) } & \\
\end{array}$ & Ton & 1603 & $\begin{array}{l}1.181 .4 \\
47,22\end{array}$ & $1.893 .859 .892,00$ \\
\hline \multicolumn{5}{|c|}{ JUMLAH HARGA } & 3.773.974.934,77 \\
\hline \multicolumn{5}{|c|}{ DIBULATKAN } & 3.773.975.000,00 \\
\hline
\end{tabular}

\section{KESIMPULAN}

Berdasarkan hasil perhitungan dan analisis yang telah dilakukan, maka diperoleh kesimpulan yaitu :

1) Berdasarkan hasil analisis metode analisa komponen Bina Marga 1987, diperoleh lapis permukaan menggunakan Laston MS $744 \mathrm{~kg}$ dengan tebal $5 \mathrm{~cm}$ dan lapis fondasi menggunakan Laston atas MS $590 \mathrm{~kg}$ dengan tebal $10 \mathrm{~cm}$. sedangkan untuk lapisan subbase digunakan sirtu/pitrun kelas B dengan tebal $5 \mathrm{~cm}$.

2) Rencana anggaran biaya pada konstruksi lapis perkerasan lentur ruas jalan Banjaran-Balamoa berdasarkan AHSP Kab. Tegal tahun 2019 dengan panjang penanganan $1000 \mathrm{~m}$ dan lebar $7 \mathrm{~m}$, diperoleh nilai total sebesar Rp. 3.773.975.000,00 (Tiga milyar tujuh ratus tujuh puluh tiga juta Sembilan ratus tujuh puluh lima ribu rupiah).

\section{DAFTAR PUSTAKA}

DPU. (1987). Petunjuk Perencanaan Tebal Perkerasan Lentur Jalan Raya Dengan Metode Analisa Komponen. Yayasan Badan Penerbit PU.

Hidayatsrf. (2016). Penerapan Geometrik Jalan Raya/Pengertian Jalan. Retrieved April Kamis, 2020, from https://id.m. wikibooks.org

Monika Natalia, F. A. (2019). Analisa Harga Satuan Pekerjaan Beton Bertulang Berdasarkan BCWP dan AHSP SNI 2016 (Proyek Pembangunan Aeon Mixed Use Apartemen 3 Sentul City Bogor). Jurnal Ilmiah Rekayasa Sipil.

Spesifikasi Umum Untuk Pekerjaan Jalan dan Jembatan. (2018). Jakarta: Direktorat Jenderal Bina Marga.

Sudarno, d. (2018). Analisis Tebal Perkerasan Jalan Raya Magelang-Purworejo KM 8 Sampai KM 9 Menggunakan Metode Bina Marga 1987. Reviews in Civil Engineering, v.02, n.1, 41-46.

Sudarno, Falakh, A. N., \& Navitasari, N. D. (2018). Evaluasi Tebal Perkerasan Jalan Raya SecangMagelang Menggunakan Metode Analisa Komponen. Jurnal Disprotek Vol. 9 No. 2, 97101.

Sukirman, S. (1999). Perkerasan Lentur Jalan Raya. Bandung: NOVA.

Umum, D. P. (1987). Petunjuk Perencanaan Tebal Perkerasan Lentur Jalan Raya Dengan Metode Analisa Komponen. Jakarta: Yayasan Badan Penerbit PU.

Wulansari, D. N. (2018). Analisis Tebal Perkerasan Lentur Menggunakan Metode Analisa Komponen Dan Metode AASHTO Pada Ruas Jalan Nagrak Kabupaten Bogor. Jurnal Kajian Teknik Sipil No. 3 Vol. 1, 22-31. 